\title{
ELECTRON MICROSCOPE STUDY ON THE SPERMATOZOON OF THE LIPHISTIID SPIDER, HEPTATHELA KIMURAI
}

\author{
Haruki ŌSAKI \\ Kumamoto City Senior High School, Kitatsuboi-machi, Kumamoto-shi, Japan
}

(Received April 3, 1969)

\begin{abstract}
Intratesticular spermatozoa of Heptathela kimurai have been examined with light and electron microscope. Living spermatozoon consists of a 20 to $25 \mu$-long spiral head and an approximately $6 \mu$-wide broad cytoplasmic portion. At the terminal end of the sperm head, there is a specialized acrosomal complex. The intact acrosome consists of an acrosomal vesicle, the lateroposterior side of which is deeply invaginated so that the whole vesicle forms a sheath around a slender acrosomal fiber. The acrosomal vesicle, except for the apical part of the vesicle, is filled with dense particulate material. Acrosomal fiber extends distally to form the spiral around the cork-screw nucleus. It is wrapped by a membranous sheath formed by an extension of the nuclear envelope. A single centriole is located in an invagination of the posterior end of the nucleus. A long flagellum coming from centriole coils 3 to 4 times around the periphery of the cytoplasmic region. Middle piece of the flagellum is enveloped by the mitochondrial sheath. In contrast to the conventional $9+2$ pattern in cilia and flagella, the Heptathela sperm flagella have the $9+3$ pattern, i.e. nine peripheral pairs plus three central tubules. Cytoplasmic region includes giant body, clusters of glycogen particles, lipids, and membranous structure.
\end{abstract}

\section{INTRODUCTION}

The liphistiid spiders are the most primitive group in the order Araneae from the viewpoint of morphology (7), cytology (25) and embryology (29, 30). They are restricted within south-eastern Asia, and grouped into eight species of Liphistius and three species of Heptathela. Heptathela kimurai is the only liphistiid found in Japan. Although spermiogenesis and spermatozoon morphology have been studied in various species of spiders with the aid of the light microscope, no morphological studies of the spermatid and spermatozoon in the liphistiid have heretofore been made. 


\section{( 2$)$}

In this paper unusual fine structures of intratesticular spermatozoa of Heptathela kimurai are fully described. Spermatozoa of higher spiders such as Agelena opulenta, Oxyopes sertatus, and Heteropoda venatoria were also studied by electron microscopy in order to compare their ultrastructures with those of Heptathela kimurai. The present electron microscopical investigation, as a first contribution to the spermatozoon morphology in the most primitive spider, might add some information to the comparative morphology and phylogeny of Arachnida.

\section{MATERIAL AND METHOD}

Sexually mature adult spiders, Heptathela kimurai, were collected in Kumamoto district, from late August to mid-September. The testes, which lie embedded on the ventral surface of the glandular mid-gut, are coiled and thread-like in shape.

For electron microscopy, testes were carefully removed from the living spider, placed in a drop of cold fixative (osmium tetroxide 2 per cent buffered at pH 7.2 with veronal acetate (18)), and then cut into several pieces under a low power binocular microscope. The material was then transferred immediately to a tube containing cold fixative and kept at $4^{\circ} \mathrm{C}$ for 1.5 to $2 \mathrm{hrs}$. After fixation, the material was dehydrated in a series of increasing concentrations of cold ethyl alcohol, and embedded in Epon 812 according to Luft (14). Sections were obtained by using the Porter-Blum ultramicrotome equipped with a glass knife, and mounted on uncoated copper grids. They were stained with uranyl acetate (28) and lead citrate (21), and were examined "with electron microscope.

For ordinary light microscopy, the material fixed in osmium tetroxide for electron microscopy was cut at $2 \mu$ thickness, and stained with Heidenhain's iron hematoxylin. To show the presence of DNA in spermatozoa, the material was fixed in Bouin's solution, cut in $10 \mu$ in thickness by ordinary paraffin method and stained with Feulgen reaction. For the detection of glycogen, the PAS reaction was made on paraffin sections ( $4 \mu$ in thickness) of material fixed in Rossman's solution. For examination of living spermatozoa, the testis was teared apart or squashed in physiological saline, and immediately examined under the microscope.

\section{RESULT}

\section{Light Microscopy}

In cross-section the ripe testis is spherical or oval in shape, 0.15 to $0.25 \mathrm{~mm}$ in diameter. Inside the wall of the testis there are many cysts containing spermatozoa or later spermatids. All the spermatozoa or the later spermatids found in each 
cyst were always exactly or very nearly in the same condition. In the center of the testis, there is a spacious testicular lumen, in which the spermatozoa were always seen (Figs. 3 and 4). This central cavity is opened to a common duct (vas deferens).

The living spermatozoon has a long spiral head which is 20 to $25 \mu$ in length and spirochaete-like in structure. The remainder of the spermatozoon consists of a cytoplasmic portion measuring about $6 \mu$ in width. In all the living specimens examined, movement of spermatozoon was never observed. Feulgen reaction showed that the elongated spiral region of the spermatozoon was strongly Feulgen positive and that the broad region was negative. This indicates clearly the presence of the nucleus in the elongated region. Several PAS-positive inclusions were found in the periphery of the broad cytoplasmic region. However, after incubation of sections in saliva, the PAS reactivity of the inclusions was markedly reduced. These results indicate that the broad cytoplasmic region contains a polysaccharide which is probably glycogen. An acrosomal fiber and a flagellar filaments observed in the electron microscope were beyond visibility under the light microscope.

\section{Electron Microscopy}

As the development of spermatid proceeds, the nucleus becomes elongated and later evaginates to form a separate head structure which is enveloped in a thin cytoplasmic layer. At about the same time that the nucleus evaginates, the nuclear material becomes filamentous in appearance, with the longitudinal orientation (Fig. 12) and later the filamentous chromatin undergoes a rapid condensation. As a result of this condensation, in the latest spermatid nucleus the filamentous chromatin is no longer discernible (Fig. 13). During this process goes on, the mitochondria and the other cytoplasmic components remain in the broad cytoplasmic region of the sperm cell and a long flagellum protruding into the cyst lumen coils itself 3 to 4 times around the periphery of the cytoplasmic portion.

The acrosomal complex of intratesticular spermatozoon consists essentially of an acrosomal vesicle (about $1.85 \mu$ in length and $0.65 \mu$ in diameter) and a long acrosomal fiber (about 100 to $160 \mathrm{~m} \mu$ in diameter). Very probably, the lateroposterior side of the acrosomal vesicle is invaginated to from a narrow, somewhat spiral, deep lumen within which is an acrosomal fiber (Figs. 2, 9, 10, and 11). The lumen enclosed, by the invaginated acrosome, except for the acrosomal fiber, appears to be empty. as it contains no other electron-scattering material. The acrosomal vesicle, except for the apical part of the vesicle, is filled with moderately electron opaque, particulate material. In the apical one-third of the vesicle, very narrow gap between 
the plasma membrane and the acrosomal membrane is flled with dense material to form an apical compound thick layer (Figs. 2 and 9). Anterior part of the inner acrosomal membrane is internally lined with electron-dense material (Figs. 2, 9, and 10). The acrosomal fiber, deeply inserted in the invagination, extends distally beyond the posterior end of the acrosomal vesicle to form the spiral around the corkscrew nucleus (Figs. 1 and 13). It is wrapped by a membranous sheath formed by an extension of the nuclear envelope (Figs. 5, 6, and 7). This spira1 acrosomal fiber extends uninterruptedly from the anterior end of acrosome to the posterior end of long nucleus. After fixation with osmium tetroxide, its substance gave no indication of longitudinal components.

A single centriole is located in a pit or invagination at the posterior end the nucleus, and the long axis of the centriole is usually parallel to the long axis of the nucleus. The centriole is a hollow, cylindrical structure and separated from the basal plate of the flagellum (Figs. 1, 7,8, and 15). The middle piece of sperm flagellum is enveloped by the mitochondrial sheath formed by the twisted helices of six (sometimes seven) elongated mitochondria (Figs. 1, 6, and 18). Dense particles that resemble glycogen are dispersed between the axial flagellar filaments and the mitochondrial sheath (Figs. 6, 7, 8, and 14).

The most striking feature of Heptathela kimurai sperm tail is that the flagellum has the axial filament complex which consistently represents the $9+3$ pattern, i.e., it consists of three central filaments and nine peripheral double filaments (Fig. 14). The peripheral nine double filaments apparently origin from the basal plate of the flagellum, but the three central filaments appear to begin a short distance from the plate (Figs. 7 and 8). Depending on the level of cross-section of the flagellum the density of axial filament complex differs. In the main piece the flagellar filaments of anterior part (Fig. 14, F2) is denser than that of posterior part (Fig. 14, F3). In the cross-section of any part of the axial filament complex, the subfiber A (Fig. 14, A), which has two arms (Fig. 14, arrows), seems to be denser than the subfiber B(Fig. 14, B), whereas the three central filaments have a density which approximates to that of the subfiber B. Subfiber A and B alternates in position around the circumference of the flagellum. The three central filaments appear as uniform tubules of about the same size as the peripheral filaments, and an electron-opaque substance fills the gap among the three central filaments (Fig. 14).

In the broad cytoplasmic region, the most conspicuous inclusion is the aggregate of dense, coarse granules which was named as "giant body" by the present author (Figs. 1, 5, 6, and 7). This body is enclosed within the delicate membrane, and is 
located in the center of the cytoplasmic region. By means of the light microscopy, it was intensively stained with Heidenhain's iron hematoxylin, whereas Feulgen and PAS reaction was negative. The origin and functional significance of this body remain unknown in the present study. Several clusters of dense glycogen particles, confined by electron-opaque membrane, are found in the peripheral portion of the cytoplasm (Figs. 1, 5, 6, and 7). These clusters may be correspond to the PASpositive inclusions which have been observed by the light microscope (see section under Light Microscopy). In addition the cytoplasmic region includes lipids and membranous structure which may be slough of the nuclear envelope (Figs. 1, 5, 6, and 7).

\section{DISCUSSION}

The lack of studies on spermiogenesis of Araneae by modern techniques of electron microscopy has made it difficult to provide a generalized structure of typical liphistiid spider sperm. The main points of interest in the study of the fine structure of intratesticular spermatozoa of Heptathela kimurai are: the fate of oval-shaped or round and relatively large cytoplasmic region containing cytoplasmic organelles and inclusions; coiled flagellum which has the $9+3$ pattern of axial filament complex; and the functional significance of specialized acrosomal complex.

According to Yoshikura $(29,30)$, "The mating season of Heptathela kimurai is September to October. At the time of pairing, the seminal fluid is transferred from each receptaculum seminis of the male palpi into the spermathecae of the female. The sperms will be retained there until the next egg laying season (late June to mid-July)." Whether or not the spermatozoon sloughs the cytoplasmic inclusions in a broad cytoplasmic region after it is deposited in the spermathecae of the female is unknown. In this study the spermatozoa are considered immature, because spermatozoa at this stage were incapable of motility. One might expect further developmental changes of the spermatozoon during its storage in the female. It is entirely possible that the flagellar axial filament complex obtains a plasma membrane before the spermatozoon sloughs the cytoplasmic inclusions and participates in fertilization.

Dense particles scattered between axial flagellar filaments and mitochondrial sheath and closely packed in electron opaque membrane are similar to the glycogen particles observed in Testacella spermatozoa (19) and human blood platelets (12). The positive PAS reaction of the periphery of a broad cytoplasmic region demonstrates the presence of a polysaccharide in this peripheral portion of the 
cytoplasm, and the decrease in staining intensity of the periphery subsequent to incubation in saliva indicates that the polysaccharide is probably glycogen. These glycogen particles are presumably available as stores to be utilized in ATP production by the mitochondria.

The $9+2$ pattern of the axial filament complex has been found in cilia and flagella of various plants and animals. It has been recognized as an indication of a genetic stability in the morphology of cilia and flagella since the pioneers in electron microscope study devoted to this problem $(10,15)$. In the extensive literature dealing with the structure of cilia and flagella published up to the present, this concept seems to be generally accepted. A few exceptions, however, were found in the sperm of certain flatworms; their flagella had a $9+1$ pattern $(6,23$, 24). There were also a few cases of aberrant or mutant flagella and cilia which differed from the $9+2$ pattern $(3,20,22)$.

In contrast to the nearly universal $9+2$ pattern in cilia and flagella, spermatozoan flagella of Heptathela kimurai have the axial filament complex that can be characterized as $9+3$ pattern. Afzelius (2) had shown that cilia in the swimming. plate of the ctenophore Mnemiopsis leydyi had the $9+3$ pattern. According to him, "The central part of the ctenophore cilia contains two tubular filaments that are arranged in a plane that is perpendicular to the ciliary beat direction. Moreover, there is a compact filament (=midfilament) that is situated close to the other two filaments and, actually, often close to the geometrical center of the ciliary cross-section.......... the midfilament......... seems to make a supporting role more likely than a contractile or a kinetic one." This pattern of ctenophore cilia is clearly different from the flagellum of Heptathela sperm, because the three central filaments do not exhibit uniform tubules. In cross-sections of ctenophore cilia, only one plane would divide the axial filament complex into mirror portions, the flagellum of Heptathela sperm, however, has radial symmetry which is bilaterally symmetric with respect to three axis.

Cilia and flagella have a fundamental two-dimensional beat or wave whose orientation is apparently determined by the central doublet of the $9+2$ axial complex $(5,8,10,13)$. The direction of beat is always perpendicular to the plane formed by an imaginary line connecting the centers of the two central microtubules. Although the motility of testicular spermatozoa of Heptathela himurai has not yet been observed, this can not rule out the possibility of some active movement within the spermathecae of the female. If there is any motility after capacitation, it must be intricate movement. The $9+3$ pattern was also found in spermatozoa of some higher 
spiders such as Agelena opulenta, Oxyopes sertatus, and Heteropoda venatoria (Ōsaki, unpublished data). To our knowledge, however, the three central microtubules in flagella and cilia have not been reported in other species. This finding, so diametrically opposed to the almost universally accepted concept of two central microtubules, suggests that another basic pattern exists. Further studies with true spiders and their close relatives, not only with the flagella of spermatozoa but with the cilia of Malpighian vessel and stercoral pocket should be rewarding.

If the smaller dimensions of the Heptathela acrosome are disregarded, its general construction bears a resemblance to that of the Mytilus acrosome (16). In both cases the acrosomal membrane is deeply invaginated at the side opposed to the nucleus, most of its contents are particulate materials, and externally it is covered by the plasma membrane. Sections through the base of Heptathela acrosome fail to reveal the presence of any special structure similar to the basal ring of the Mytilus spermatozoon. It may be significant, however, that in both acrosomal complex the rod inserted within deep invagination ("axial rod" in Mytilus, "acrosomal fiber" in Heptathela) is found. Nijima et al. (17) have reported that when the Mytilus spermatozoon comes into contact with the egg, the acrosomal vesicle opens and exposes the invaginated portion of the acrosomal membrane (=rudiment of acrosomal process) within which the axial rod elongates. As to the function of the Heptathela acrosomal fiber, it seems to have the same function as in the Mytilus axial rod. In the apical region of the Heptathela acrosome a thick layer of dense material was found (Fig. 2, MPA). This layer may correspond to the "trigger layer" studied by Dan et al. (9) in the sea urchin acrosome.

In the acrosomal complex of Heptathele the most odd apparatus is the acrosomal fiber which is twisted around the elongated nucleus. Although the anterior end of the fiber is inserted in the lumen formed by the invagination of acrosomal membrane, there is no evidence that the fiber is derived from the acrosome. Several authors $(4,11,26,27)$ described intra-or extranuclear filament, which runs along the whole length of remarkably elongated spermatid or sperm nucleus. Mature encysted testicular spermatozoa of pseudoscorpion, Hysterochelifer meridinus, was observed by Tuzet et al. (27) in detail. They found "la formation spiralée autour du noyau," which bears a surprising likeness to that found in Heptathela. Although the origin of the acrosomal fiber is unknown, it is speculated thet such apparatus may facilitate the activity of spermatozoa, because the apparatus is present along the full length of remarkably elongated sperm nucleus. 


\section{ACKNOW LEDGEMENTS}

Electron micrographs for the present study were made with Hitachi HU-11A electron microscope at the Department of Anatomy, Faculty of Medicine, Kumamoto University. The author is deeply grateful to Dr. C. Ōura for the privilege of using this instrument and other equipment at the Department, and for his invaluable help and technical guidance in electron microscopy throughout the course of this investigation. To Mr. T. Kubota I am indebted for his help in taking the electron micrographs. Deep gratitude is expressed to Professor M. Yoshikura, Department of Biology, Faculty of Science, Kumamoto University, for his criticism of the manuscript and encouragement. This study was supported by Grant from the Shimonaka Commemoration Foundation and Kumamoto City Senior High School.

\section{REFERENCES}

1. Afzelius, B., Electron microscopy of the sperm tail, J. Biophysic. and Biochem. Cytol., 1959, 5, 269.

2. Afzelius, B. A., The fine structure of the cilia from ctenophore swimming-plates, J. Biophysic. and Biochem. Cytol., 1961, 9, 383.

3. Afzelius, B. A., Cilia and flagella that do not conform to the $9+2$ pattern. I, Aberrant numbers within normal populations, J. Ultrastruct. Research, 1963, 9, 381.

4. André, J., Existence d'un axe nucléaire dans le spermatozoïde de la Limule; ses relations avec la réaction acrosomienne, J. Microscopie, 1963, 2, 21.

5. Bishop, D.W., Sperm motility, Physiol. Rev., 1962, 42, 1.

6. Bonsdorff, C.-H. v., and Telkkä, A., The spermatozoon flagella in Diphyllobothrium latum (Fish tapeworm). Z. Zellforsch. u. mik. Anat., 1965, 66, 643.

7. Bristowe, W.S., and Millot, J., The liphistiid spiders, Proc. Zool. Soc., London, 1932, 1015-1057.

8. Cleland, K. W., and Lord Rothschild, The bandicoot spermatozoon: an electron microscope study of the tail, Proc. Roy. Soc. London, Series B, 1959, 150, 24.

9. Dan, J. C., Ohori, Y., and Kushida, H., Studies on the acrosome. VIr. Formation of the acrosomal process in sea urchin spermatozoa, J. Ultrastruct. Research, $1964,11,508$.

10. Fawcett, D.W., and Porter, K.R., A study of the fine structure of ciliated epithelia, J. Morph., 1954, 94, 221.

11. Follenius, E., Particularités de structure des spermatozoïdes de Lampetra planeri, 
J. Ultrastruct. Res., 1965, 13, 459 .

12. Hattori, A., Some observations on the ultrastructure of blood platelets in normal and some clinical conditions, with special references to its abnormality, $J$. Electron Microscopy, 1967, 16, 239.

13. Lindah1, P. E., and Drevius, L.-O., Observations on bull spermatozoa in a hypotonic medium related to sperm mobility mechanisms, Exp. Cell Research, $1964,36,632$.

14. Luft, J. H., Improvements in epoxy resin embedding methods, J. Biophysic. and Biochem. Cytol., 1961, 9, 409.

15. Manton, L., and Clarce, B., The structure of plant cilia, J. Exp. Bot., 1952, 3, 265.

16. Niijima, L., and Dan, J., The acrosome reaction in Mytilus edulis. I. Fine structure of the intact acrosome, J. Cell Biol., 1965, 25, 243.

17. Niijima, L., and Dan, J., The acrosomal reaction in Mytilus edulis. II. Stages in the reaction, observed in supernumerary and calcium-treated spermatozoa, $J$. Cell Biol., 1965, 25, 249.

18. Palade, G. E., A study of fixation for electron microscopy, J. Exp. Med., 1952, 95, 285.

19. Personne, P., et André, J., Existence de glycogène mitochondrial dans le spermatozoïde de la testacelle, J. Microscopie, 1964, 3, 643.

20. Randall, J., Wair, J. R., Hopkins, J. M., and Mc Vittir, A., A single-gene mutation of Chlamydomonas reinhardii affecting motility: A genetic and electron microscopic study, Nature, 1964, 203, 912.

21. Reynolds, E. S., The use of lead citrate at high $\mathrm{pH}$ as an electron-opaque stain in electron microscopy, J. Cell Biol., 1963, 17, 208.

22. Satir, P., On the evolutionary stability of the $9+2$ pattern, J. Cell Biol., 1962, 12,181 .

23. Shapiro, J. E., Hershenov, B. R., and Tulloch, G. S., The fine structure of Haematoloechus spermatozoan tail, J. Biophysic. and Biochem. Cytol., 1961, 9, 211.

24. Silveira, M., and Porter, K. R., The spermatozoids of flatworms and their microtubular systems, Protoplasma, 1964, 54, 240.

25. Suzuki, S., Cytological studies in spiders. III. Studies on the chromosomes of fifty-seven species of spiders belonging to seventeen families, with general considerations on chromosomal evolution. J. Sci. Hiroshima Univ., 1954b Ser. BI, 15, 23.

26. Tuzet, O., et Manier, J. F., Recherches sur la spermiogenese de araignées: Araneus cornutus, Tetragnatha pinicola, Philodromus poecilus et Chiracanthium sp, Ann. 


\section{(10)}

Sci. Nat. Zool., 1959, 1, 91.

27. Tuzet, O., Manier, J. F., et Boíssin, L., Étude du spermatozoïde mûr enkysté d' Hysterochelifer meridianus (L. Koch) (Arachnide, Pseudoscorpion, Cheliferidae), C. R. Acad. Sc., 1966, 262, 376.

28. Watson, M. L., Staining of tissue sections for electron microscopy with heavy metals, J. Biophysic. and Biochem. Cytol., 1958, 4, 475.

29. Yoshikura, M., Embryological studies on the liphistiid spider, Heptathela kimurai, Part I. Kumamoto Jour. Sci., 1954. Ser. B, 41.

30. Yoshikura, M., Embryological studies on the liphistiid spider, Heptathela kimurai, Part II. Kumamoto Jour. Sci., 1955, Ser. B, 2, 1.

\section{EXPLANATION OF PLATES}

\section{Abbreviation Used on Plates}

AF : acrosomal fiber

AM: acrosomal membrane

AL: apical compound thick layer $(\mathrm{PM}+\mathrm{MPA}+\mathrm{AM})$

BP: basal plate

C: centriole

CA : cavity of acrosomal vesicle

$\mathrm{CL}$ : cyst lumen

$\mathrm{F}$ : flagellar filaments

GB: giant body

GC: cluster of glycogen particles

GP: glycogen particles

L: lipid

LA: lumen formed by invagination of acrosomal membrane
MeS: membranous structure

MI: material lining inner acrosomal membrane

MPA: material lying between plasma membrane and acrosomal membrane

MS: mitochondrial sheath

$\mathrm{N}$ : nucleus

NE: nuclear envelope

NI: posterior nuclear invagination

OM: osmiophilic material of acrosomal vesicle

PM: plasma membrane

TC: testis cyst

\section{Plate 1}

Fig. 1. Three-dimensional reconstruction of the broad cytoplasmic region of Heptathela kimurai spermatozoon. The greater part of the head and the fiagellum are cut away.

Fig. 2. Diagramatic longitudinal section of Heptathela kimurai spermatozoon showing details of intact acrosome. 


\section{Plate 2}

Figs. 3 and 4 . Light micrographs of cross-section through the testis of an adult Heptathela kimurai. Spacious testicular lumen (TL) is filled with spermatozoa. Note the broad cytoplasmic region (CR) and the spirochaete-like head (arrows). Osmium fixation, Epon embedding, $2 \mu$ section, Heidenhain's iron hematoxylin stain. $\times 670$.

Fig. 5. This relatively low power, electron micrograph of several spermatozoa of the testis cyst shows sections at various regions. Cross (N1) and oblique (N2) sections of elongated head nucleus with acrosomal fiber and oblique sections of broad cytoplasmic region containing posterior portion of nucleus (N3), flagellar filaments, giant body, clusters of glycogen particles and lipid are clearly visible. Note that the nuclear envelope closely invests the acrosomal fiber. The plasma membrane of mature cyst is characterized by numerous short microvilli (MV); all the spermatozoa in mature cyst have never protruded flagellum, but coiled one. Immature cyst lumen in the upper right part of the figure has transections of protruding flagellum of three spermatids; each flagellar filaments is covered only by the plasma membrane or flagellar membrane. $\times 11,500$.

\section{Plate 3}

Fig. 6. Longitudinal section of a broad cytoplasmic region almost through its central plane. Note the sections of nucleus with acrosomal fiber, the helixlike structure of mitochondrial sheath (arrows), glycogen particles scattered between the sheath and flagellar filaments and longitudinal section of flagellar filaments (LF). A single giant body, several clusters of glycogen particles, closely packed in electron-opaque membrane, lipids and membranous structure can also be seen. The slightly slanted section missed the centriole. $\times 23,000$.

\section{Plate 4}

Fig. 7. A slightly oblique, longitudinal section of a broad cytoplasmic region showing a single centriole and the basal plate of the flagellar filaments. The lines " $a$ " and " $b$ " define the planes of the sections shown in Figs. 15 and 16 respectively. Three oblique sections of flagellar filaments are clearly observed at the upper right part and the lower left part in the periphery of the cytoplasmic region. $\times 22,700$.

Fig. 8. A glancing section of a single centriole and proximal part of the flagellar filaments. The lines " $\mathrm{b}$ " and " $\mathrm{c}$ " correspond to the planes of the sections shown in Figs. 16 and 17 respectively. $\times 21,300$. 


\section{Plate 5}

Fig. 9. Longitudinal section through an acrosome. The lines " $a$ " and " $b$ " would give approximately the sections shown in Figs. 10 and 11 respectively (see text and Fig. 2). $\times 20,000$.

Fig. 10. An approximate cross-section at the level of anterior part of inner acrosomal membrane and apical compound thick layer. A section in the plane of the line " $a$ " shown in Fig. 9 would give approximately the section shown in this figure. $\times 20,000$.

Fig. 11. Transverse section of mid-part of an acrosome. This picture may correspond to a section in the plane of the line " $b$ " shown in Fig. 9. $\times 20,000$.

Fig. 12. Longitudinal section through the spermatid nucleus, which is evaginating from the broad cytoplasmic region. Note the nucleus being composed of fine filamentous chromatin. Only this electron micrograph is from testis fixed in $3 \%$ glutaraldehyde ( $\mathrm{pH} 6.8$ ) followed by $1.25 \%$ osmium tetroxide ( $\mathrm{pH} 7.2$ ). Fixing solutions were buffered in $0.1 \mathrm{M}$ Sorensen's phosphate buffer (final molarity). $\times 13,500$.

Fig. 13. Longitudinal section through evaginated head nucleus of latest spermatid showing extremly electron-opaque nucleoplasm. The nucleus studded with sections of acrosomal fiber is enclosed by narrow cytoplasm in which the elongated endoplasmic reticulum (arrows) and vacuoles (V) are visible. $\times 15,000$.

Fig. 14. Relatively high resolution electron micrograph showing cross-sections at different levels of only one flagellum coiled around the periphery of broad cytoplasmic portion. Details are presented in the text. A; subfiber A, B; subfiber $B, F 1$; middle piece, F2; supposed anterior part of main piece, F3; supposed posterior part of main piece, arrows; arms of Afzelius (1). $\times 60,000$.

Fig. 15. Transverse section through the centriole at the level of " $a$ " in Fig. 7 . $\times 20,000$.

Fig. 16. Somewhat diagonally transverse section through distal part of flagellar flaments at the level of " $b$ " in Figs. 7 and $8 . \times 20,000$.

Fig. 17. Cross section of the posterior part of the nucleus at the level of " $c$ " in Fig. $8 . \times 20,000$.

Fig. 18. Cross-section through mitochondrial sheath. Flagellar filaments is enveloped by six oval-shaped mitochondria. $\times 20,000$. 


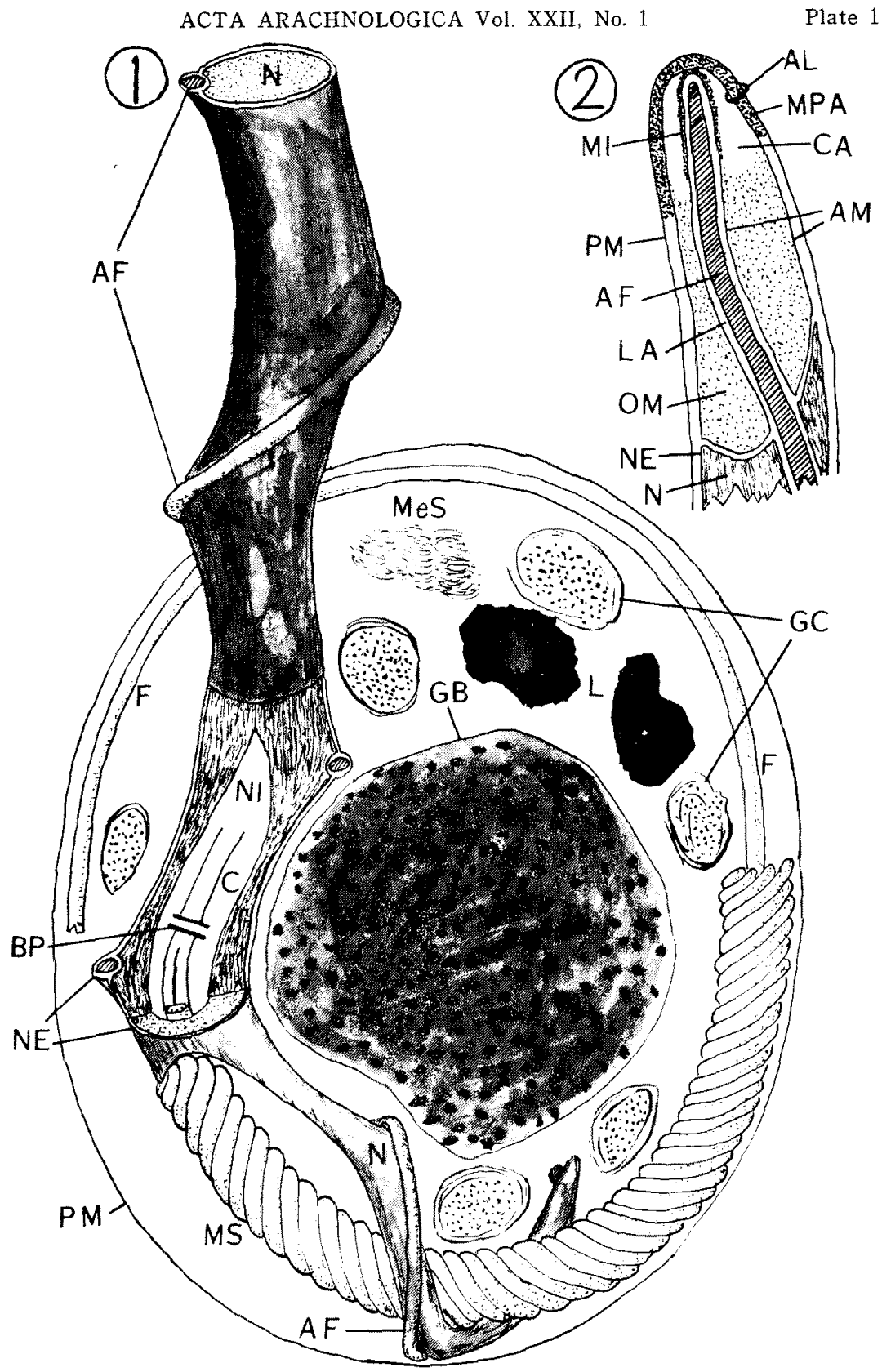




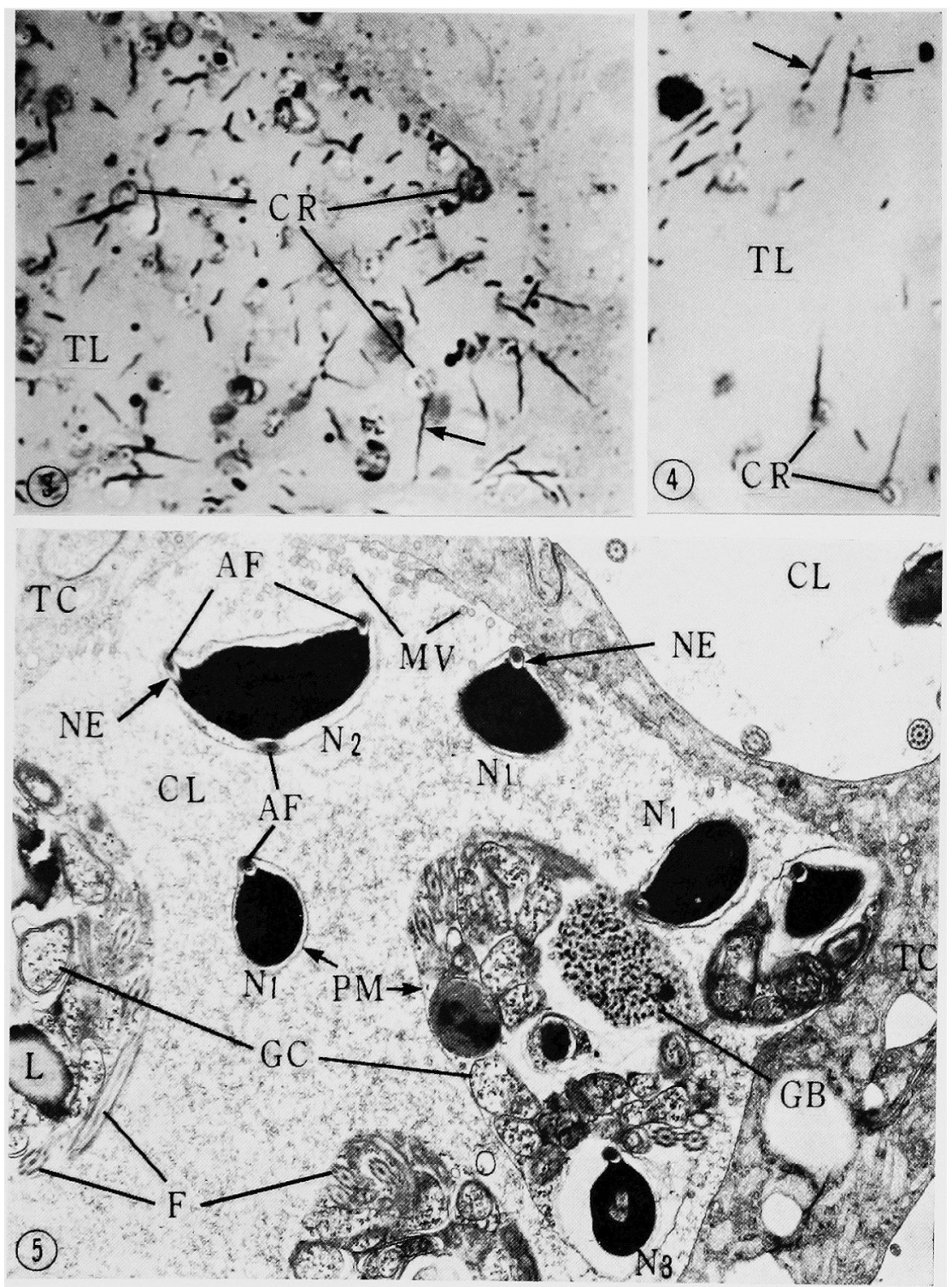


ACTA ARACHNOLOGICA Vol. XXII, No. 1

Plate 3

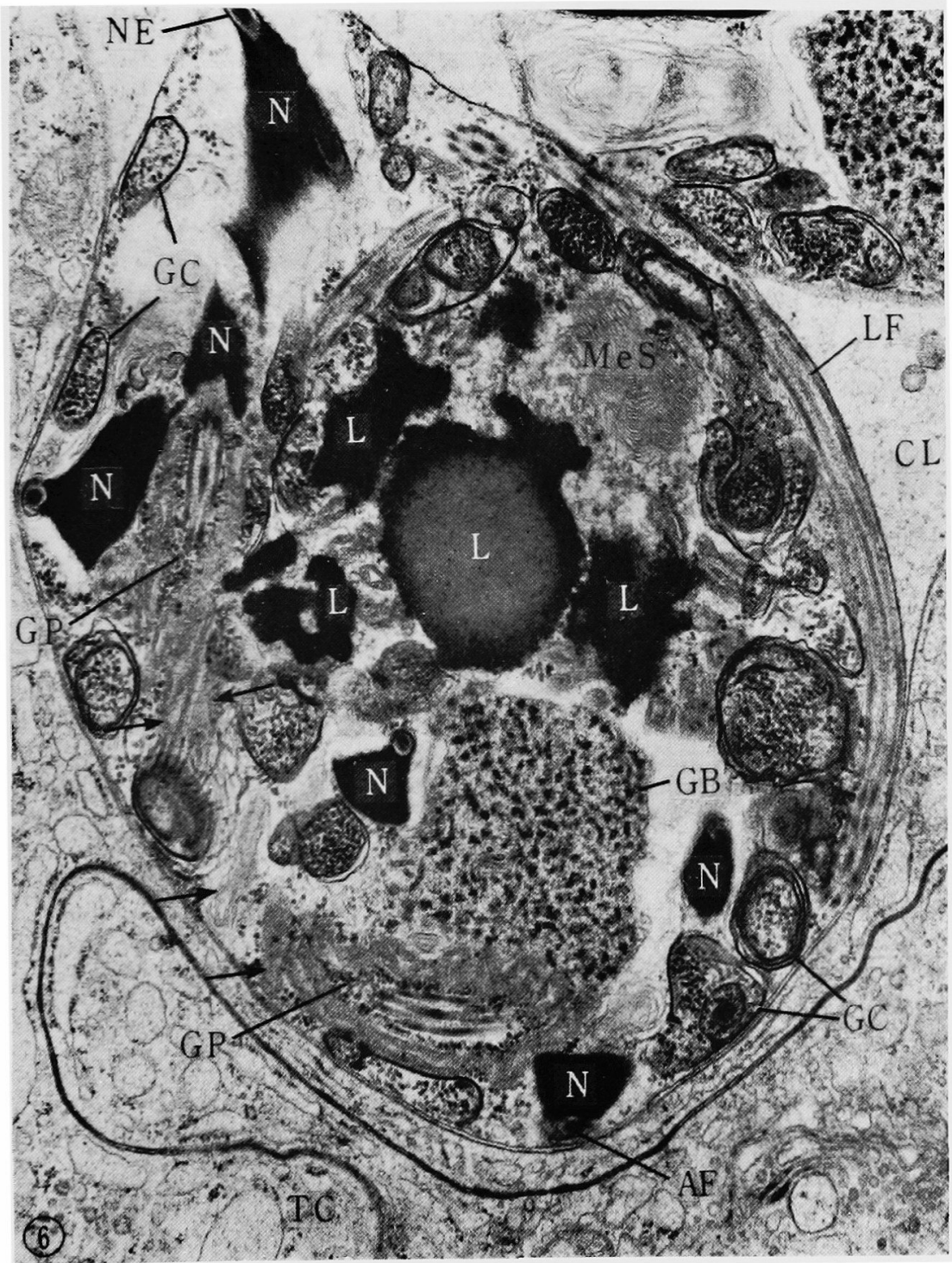


ACTA ARACHNOLOGICA Vol. XXII, No. 1

Plate 4
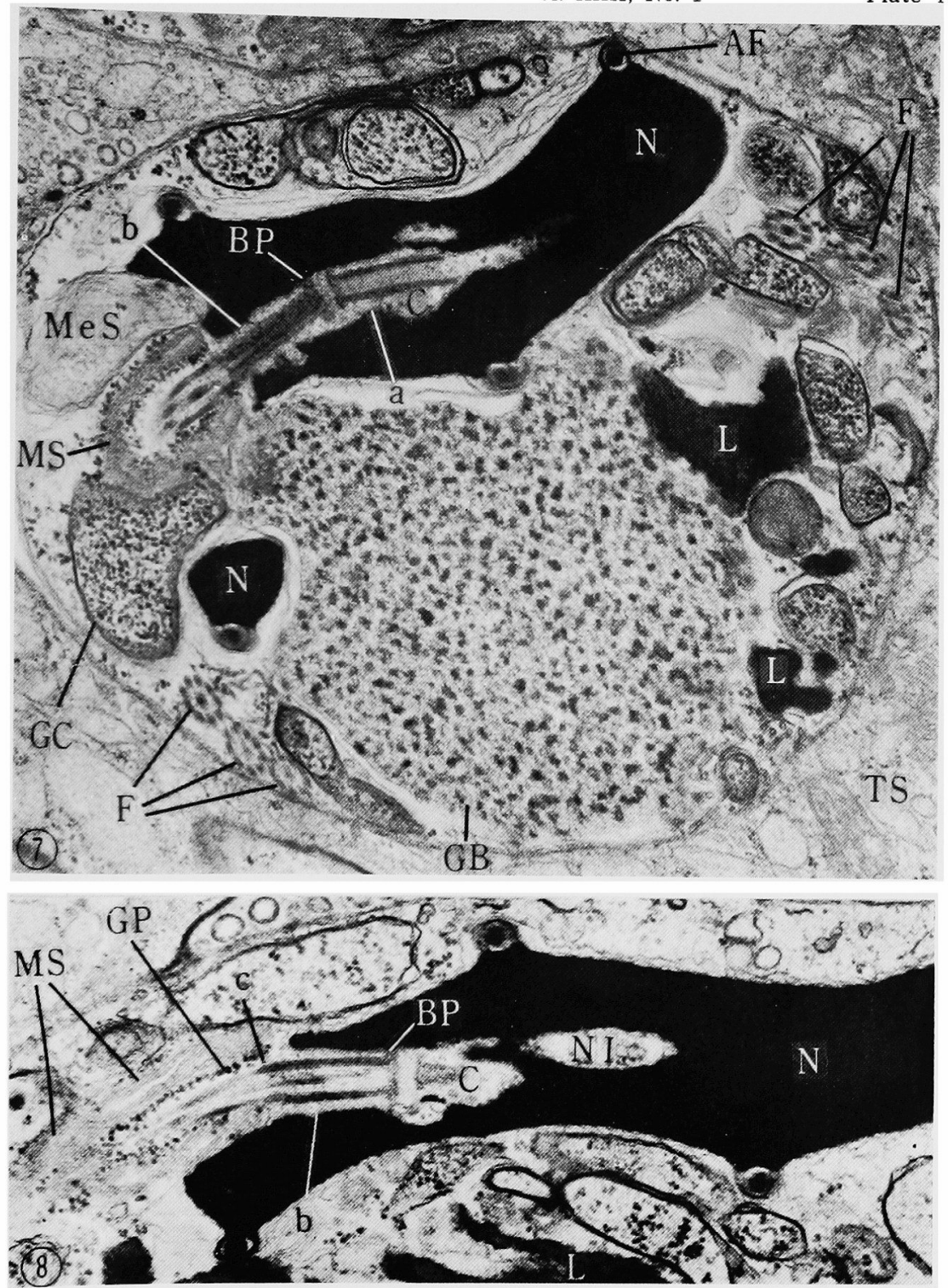
ACTA ARACHNOLOGICA Vol. XXII, No. 1

Plate 5
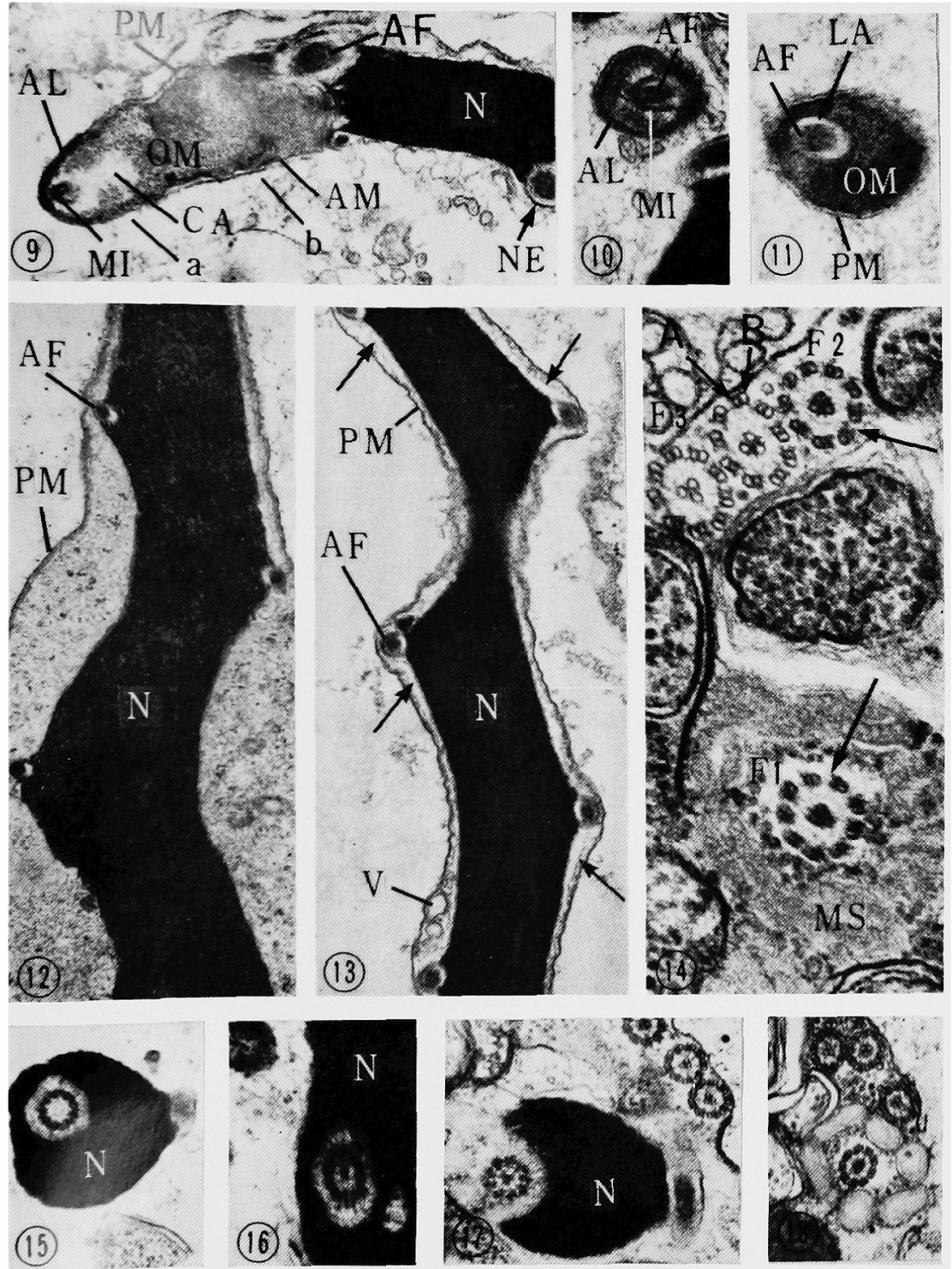
摘

要

\section{キムラグモ精子の電子顕微鏡的研究 \\ 大 崎 春 榯}

熊本市北坪井町15 熊本市立高等学校

キムラグモの精巣内精子は，幅約 $6 \mu$ ○球乃至棈円球状の細胞質膨大部之，乙れから突

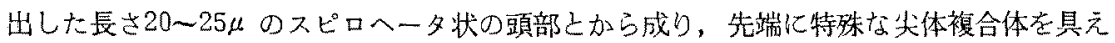

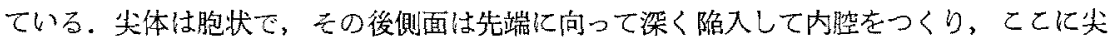
体瀻維力㧴入されている，尖体胞は先端部を除くと電子密度の高い顆粒物質で满たされて

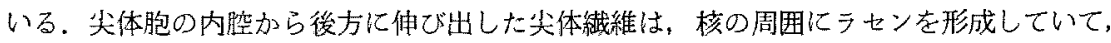
核膜起原の鞘によって包まれている，核の後端近くの宿入部には 1 個の中心粒があり，こ れから出た 1 本の長い鞭毛は，緗胞質膨大部の周縁に3〜4回とぐるを巻いている。鞭毛 中間部はミトコンドリア鞘に包まれている。動植物を通じて鞭毛あるいは瀻毛の横断面が 普遍的に 9+2 型でるのに詨し，キムラグモの精子鞭毛は $9+3$ 型，つまり，9対の周 因束上 3 本の中心微小細管とて構成されている，細胞質膨大部には giant body，膜に包ま れたグリコーゲン顆粒群，脂質及び核膜に由来したものと考えられる膜㯃構造物等が含ま れている. 